departments are concerned and neither will move because of the other. On the one hand, the Department of Health and Social Security feels compelled to halt at the farm gate; and, on the other, the Ministry of Agriculture, Fisheries, and Food regards salmonellosis as being, in terms of overt disease, a human rather than an animal problem. Both of these central departments may be happily inclined to pass the matter to local government authorities in the hope that their so-called "proper officers" will accept the duty as belonging to them. Perhaps, indeed, that is the correct administrative position. If so, it is no more than a recipe for inaction. Preventive medicine in communicable diseases calls for activity by medical and veterinary epidemiologists able to act on a regional and even a national scale. With the Public Health Laboratory Service and the Veterinary Investigation Service, we are not lacking in the basic essentials for constructive action. But how much longer must we wait for someone to knock the heads of the two responsible Government departments together and order them to get on with the job of preventing what is preventable and should be prevented ?

It is improbable, moreover, that salmonellosis is the only example of an animal infection that could and should be eliminated by better intelligence and proper application of it -not for the sake only of mere humans but also for animal health and welfare, and for the economics of farming and food-processing.

1 The Times, 5 January 1976, p 12.

2 Veterinary Record, 1975, 97, 353.

\section{First aid in acute myocardial infarction}

The facts speak for themselves. Some $40-75 \%$ of deaths from myocardial infarction occur within an hour of the onset of symptoms, and some $60 \%$ of all coronary deaths occur outside hospital. ${ }^{1-4}$ The saving of life by bringing sufferers to coronary care units is small compared with this initial loss, and no foreseeable improvements in hospital treatment will greatly affect the total mortality. Techniques such as use of hyperbaric oxygen or aortic balloon pumping cannot be expected to make a dramatic impact on the prognosis of patients who qualify for such measures by reason of extensive necrosis, for if they survive they are likely to live precariously on the verge of heart failure or further infarction.

The patients to save are those who die from arrhythmia at the start of their attack, and it is these that the mobile coronary care unit may help. Dewar ${ }^{5}$ reported the existence of seven such units in the United Kingdom this year, and the training of ambulance men in the interpretation of ECGs and in resuscitation has been pioneered at Brighton. ${ }^{6}$ In a recent report ${ }^{7}$ on the care of the patient with coronary heart disease the Royal College of Physicians and the British Cardiac Society agreed that current facilities are inadequate and recommended the development of further mobile units. There are many reasons why this has been slow to come about. The initiative rests with no single individual; to organise such a service may take staff from the wards and disrupt their routine or medical cover; and, not unimportant, some scepticism lingers from the knowledge that more often than not the patient or his relatives have already delayed calling aid and that a further 15 or 20 minutes in transit will seldom prove calamitous. Such reflections are familiar to physicians in provincial centres with resources stretched already and reluctant to assume yet another commitment. Yet if they wish encouragement, or at least a wealth of information on the topic, they should read the report ${ }^{8}$ by the pioneers of the mobile coronary care unit in Belfast, in which an impressive case is made out for such enterprises with the conclusion that the addition of a mobile unit can treble the impact of the hospital coronary unit on the community mortality.

The Belfast authors discuss the management of dysrhythmias, autonomic disturbance, and shock, but, as in most publications on the management of the acute infarct, their comments presuppose some specialist skill together with an electrocardiogram and its correct interpretation. Have recent advances in coronary care modified the advice to the general practitioner waiting with his patient for the ambulance to arrive and relying on bedside examination only? Of all the measures recommended for special circumstances there is not one which, used injudiciously, might not do more harm than good. A safe guide to intervention is thus hard to draw up, and the best rule may well be that the least is the safest, unless quick action to save the patient becomes imperative. Reassurance is always important, and pain must be relieved, perhaps with diamorphine ( $5 \mathrm{mg}$ intravenously) as first choice. Though most patients will be better supine, this will not apply to those in distress from pulmonary oedema. Cuffing the thighs or even venesection may still have a place in extreme dyspnoea. Intravenous frusemide ( 40 to $80 \mathrm{mg}$ ) can seldom do harm and may lower cardiac filling pressure before its diuretic benefit is felt. Aminophylline ( 250 to $500 \mathrm{mg}$ ) should be used with caution and injected intravenously slowly over some 15 minutes. Hypotension can sometimes be improved by raising the supine patient's legs, but few physicians now employ intravenous pressor drugs. Reactive hypertension from sympathetic overactivity may be harmful by increasing ventricular work and oxygen demand, ${ }^{10}$ but there will seldom be justification for administering potent hypotensive drugs before the patient's arrival in hospital.

The heart rate should be counted by auscultation at the apex, lest it be underestimated in rapid irregular tachycardias or in coupling, when heart block may be wrongly surmised. If the rate is physiological no drug should be given. There seems no clear mandate for the prophylactic use of lignocaine, procainamide, or the newer drug mexiletine. If the rate is unduly slow (say, under 45 per minute) one cannot tell without an ECG whether the rhythm is a sinus bradycardia, junctional rhythm, or heart block; but if the patient has signs of low cardiac output good rather than harm will more often be done by giving atropine sulphate $(0.3$ to $0.6 \mathrm{mg}$ intramuscularly or intravenously). On the other hand, the acceleration of the heart from unopposed sympathetic activity has been known to result in ventricular fibrillation or other tachyarrhythmias. ${ }^{811}$ For a patient in jeopardy from tachycardia (a rate of over 150 per minute) both intravenous practolol $(5$ to $10 \mathrm{mg})$ and verapamil $(10 \mathrm{mg})$ are relatively safe drugs which may slow an ectopic rhythm or restore sinus rhythm and are perhaps more acceptable today than intravenous glycosides, especially when direct current shock may be employed later. Precordial percussion or external cardiac massage may save a patient with extreme bradycardia or asystole, but the great life-saver in acute myocardial infarction remains the defibrillator.

${ }^{1}$ Bainton, C R, and Peterson, D R, New England fournal of Medicine, $1963,268,569$. 
${ }^{2}$ Gordon, T, and Kannel, W B, fournal of the American Medical Association, $1971,215,1617$

${ }^{3}$ Armstrong, A, et al, British Heart fournal, 1972, 34, 67.

4 McNeilly, R H, and Pemberton, J, British Medical fournal, 1968, 3, 139.

5 Dewar, H A, Fournal of the Royal College of Physicians, 1975, 9, 173.

6 White, N M, et al, British Medical fournal, 1973, 3, 618

7 Report of Joint Working Party, Fournal of the Royal College of Physicians, $1975,10,5$.

${ }^{8}$ Pantridge, J F, Geddes, J S, and Webb, S W, The Acute Coronary Attack. Tunbridge Wells, Pitman Medical, 1975.

9 Dikshit, K, et al, New England Fournal of Medicine, 1973, 288, 1087.

10 Shell, W E, and Sobel, B E, New England fournal of Medicine, 1974, 291, 481.

11 Das, G, Talmers, F N, and Weissler, A M, American fournal of Cardiology, $1975,36,281$.

\section{Whither scabies?}

Scabies occurs in epidemics, and, though it is still seen fairly often in Britain, there is reason to hope that the condition may soon become much less common. At the start of the second world war the mode of transmission of scabies was not fully understood, and in 1941 there were, according to Mellanby, ${ }^{1}$ over one million people in Britain with scabies. Mellanby's war-time experimental work on scabies transmission in volunteer conscientious objectors showed that scabies is not strictly a venereal disease and that a brief sexual encounter is less likely to transmit the infection than a more prolonged platonic sharing of a bed. Furthermore, his work showed that not only did regular bathing have little protective value but also that infrequent laundering of clothing and bedding did not increase the rate of transmission.

These facts suggested that the epidemic of scabies had less to do with wartime living conditions than had previously been believed. The disease had admittedly also been a scourge during the first world war, but a study of the children treated each year at a London cleansing centre had shown that the incidence of scabies had remained unchanged until 1920, when it had declined rapidly. ${ }^{2}$ Scabies was uncommon during the next 10 years, but it began to be seen more frequently in 1930, and the incidence rose precipitously again in 1937, well before the second world war started. The epidemic continued for the next 12 years, but the disease declined sharply in $1949^{3}$ and maintained a relatively low profile until 1964, when its incidence began to rise once more. ${ }^{4}$

Shrank and Alexander ${ }^{4}$ argued in 1967 that increased sexual promiscuity was unlikely to explain that latest increase, since there had been no concomitant increase in gonorrhoea or syphilis during the period of their study. Increased resistance of the mite to treatment was also excluded as a possibility on the grounds that no cases failed to respond to correct treatment. They also pointed out that each of the recent epidemics has lasted 10-15 years, with a similar quiescent period between epidemics. The highest incidence of scabies occurs in the age range from 15 to 30 years, so the facts are consistent with the theory that the "herd immunity" of the population gradually increases during an epidemic, and that afterwards about 15 years have to elapse for the partially immune population to be replaced by non-immune individuals.

Indeed, the concept of partial immunity to scabies was introduced by Mellanby, ${ }^{5}$ who showed that it is more difficult to induce a second attack of scabies and that during an established second attack fewer mites are found. The importance of immune responses in scabies is also suggested by the observation that the disease can be reactivated by methotrexate. ${ }^{6}$ A particularly severe variant called Norwegian scabies has been reported in patients with a specific anergy ${ }^{7}$ and in patients receiving immunosuppressive drugs. ${ }^{8}$ Some supportive laboratory evidence has come from a recent study showing that patients with scabies tend to have a low serum IgA concentration; if the serum values correlated with low IgA concentrations in the skin secretions, this might predispose to scabies infection. ${ }^{9}$ The possibility that the low IgA concentration was the result rather than the cause of the infection was not excluded, but the decrease was noted in early as well as late cases, and skin diseases are more usually associated with an increase in serum IgA. ${ }^{10}$ The relation between the serum IgA levels and the herd immunity to scabies remains to be elucidated.

If scabies runs true to form the present mild epidemic, which started in 1964, should be over by 1979 . Unfortunately, data from other countries show that the 30-year cycle is by no means constant, ${ }^{11}$ and it may well be that scabies has not been common enough in Britain in recent years for herd immunity to have developed.

${ }^{1}$ Mellanby, K, Human Guinea-Pigs. London, Merlin Press, new edn, 1973.

2 Gray, A M H, British fournal of Dermatology and Syphilis, 1941, 53, 148.

${ }^{3}$ Epstein, E, Archives of Dermatology, 1955, 71, 192.

${ }^{4}$ Shrank, A B, and Alexander, Suzanne L, British Medical Fournal, 1967, 1,669 .

Mellanby, K, Parasitology, 1944, 35, 197.

${ }^{6}$ Burrows, D, Bridges, J M, and Morris, T C M, British fournal of Dermatology, 1975, 93, 219.

${ }^{7}$ Burks, J W Jr, Jung, R, and George, W M, Archives of Dermatology, 1956, 74, 131

${ }^{8}$ Paterson, W D, Allen, B R, and Beveridge, G W, British Medical fournal, 1973, 4, 211.

${ }^{9}$ Hancock, B W, and Ward, M, Fcurnal of Investigative Dermatology, 1974, 63,482 .

10 Lai, A, Fat, R F M, and van Furth, R, Clinical and Experimental Immunology, 1974, 17, 129.

11 Orkin, M, Fournal of the American Medical Association, 1971, 217, 593.

\section{Vaginal candidosis}

Symptoms resulting from infections of the vagina with yeasts are a growing problem among patients attending general practitioners, gynaecologists, genitourinary physicians, and venereologists. The usual cause is the fungus Candida albicans, but in a minority of cases symptoms may be due to Torulopsis glabrata. ${ }^{2}$ Candida is now the most common infectious agent found in women attending clinics for sexually transmitted diseases. ${ }^{13}$ For example, ${ }^{4}$ in 1973 in England and Wales 27545 cases were diagnosed in women at the clinics, an increase of $25 \%$ over 1971 ; the corresponding figure for men was 5058 cases, an increase of $68 \%$.

Whether or not clinical disease with symptoms results from infection depends on host factors, but little is known about the virulence of different strains of fungi. Factors such as glycosuria, diabetes, obesity, pregnancy, and the recent ingestion of antibiotics or steroids and other immunosuppressant agents have been known for some time to favour the growth of fungi in the vagina. Even so, the role of oral contraceptive pills is more controversial, particularly since the introduction of those with a lower oestrogen content.

The diagnosis can be established easily by identification of the mycelium and yeast spores on Gram-stained slides of specimens from the vaginal wall and cultures using a maltosepeptone agar such as Sabouraud's medium. One of the more difficult problems is to assess the meaning of asymptomatic candidosis in women, for the condition is quite frequently 